\title{
Bioatividade das substâncias húmicas extraídas de solos manejados com integração, lavoura, pecuária e floresta
}

\author{
Marihus Altoé Baldotto ${ }^{1}$, Aline da Costa Souza ${ }^{1}$, Maria Celuta Machado Viana ${ }^{2}$ \\ Débora Durães de Almeida ${ }^{1}$, Lílian Estrela Borges Baldotto ${ }^{l}$
}

$10.1590 / 0034-737 X 201764050012$

\section{RESUMO}

A matéria orgânica humificada apresenta bioatividade semelhante à das auxinas. Contudo, são necessárias informações sobre a capacidade de estímulo vegetal das substâncias húmicas extraídas de solos manejados com sistemas integrando lavoura, pecuárias e florestas. O objetivo deste trabalho foi avaliar o desempenho inicial do milho em resposta à aplicação de concentrações de substâncias húmicas isoladas em solos manejados com sistema de integração lavoura, pecuária e florestas, aplicadas por via da semente. Sementes de milho variedade AG 1051 foram tratadas por 16 horas, em soluções contendo 0, 10, 20, 30, 40 e $80 \mathrm{mmol} \mathrm{L}^{-1}$ de carbono na forma de substâncias húmicas. Em seguida, foram plantadas em vasos de $1 \mathrm{dm}^{3}$, com solo corrigido e fertilizado, em casa de vegetação. Foram avaliadas características de crescimento da parte aérea e do sistema radicular. Observou-se que as substâncias húmicas extraídas de solos submetidos a integração lavoura, pecuária e florestas apresentaram efeitos positivos no desempenho inicial do milho, incrementando o acúmulo de matéria seca das plantas, em comparação com o efeito das substâncias extraídas de solos do controle, na área degradada inicial (133\%), do cerrado (29\%), bem como do eucalipto (30\%) e da pastagem plantada solteira $(56 \%)$.

Palavras-chave: Zea mays L.; matéria orgânica; regulador de crescimento de plantas; sistemas agroflorestais.

\section{ABSTRACT \\ Bioactivity of humic substances extracted from soils managed with integration of agriculture, livestock, and forestry}

The humified organic matter promotes biostimulating effect such as auxins. However, information is needed on plant stimulation capacity of humic substances from soils managed with systems integrating crops, livestock and forests. The aim of this study was to evaluate the initial performance of maize in response to the application of increasing concentrations of isolated humic substances from soils managed with integrated system of crop, livestock and forests, applied at seed, comparing them also with humic substances isolated from soil with eucalyptus and isolated pasture and with a Cerrado adjacent area. The corn seeds were treated for 16 hours in solutions containing 0 , 10, 20, 30, 40, and $80 \mathrm{mmol} \mathrm{L}^{-1}$ of $\mathrm{C}$ from humic substances. Then, the seeds were planted in pots of $1 \mathrm{dm}^{3}$ containing corrected and fertilized soils, in greenhouse. Growth characteristics of shoot and root systems were evaluated. The results showed that the humic substances extracted from soils with integration of crop, livestock and forests have positive effects on the initial performance of corn, superior to those observed under control (133\%), Cerrado (29\%), eucalyptus (30\%), and isolated pasture (56\%).

Key words: Zea mays L.; organic matter; plant growth regulator; agroforestry systems.

\footnotetext{
Submetido em 29/10/2015 e aprovado em 26/09/2017.

' Universidade Federal de Viçosa, Instituto de Ciências Agrárias, Florestal, Minas Gerais, Brasil. marihus@ufv.br; aline.souza@ufv.br; debora.duraes@ufv.br; lilian.estrela@ufv.br

2 EPAMIG, Unidade Regional Centro Oeste, Prudente de Morais, Minas Gerais, Brasil. mcv@epamig.br

*Autor para correspondência: marihus@ufv.br
}

Rev. Ceres, Viçosa, v. 64, n.5, p. 540-547, set/out, 2017 


\section{INTRODUÇÃO}

As substâncias húmicas da matéria orgânica atuam no enraizamento de diversas plantas de interesse agronômico, assim como exercem efeitos estimulantes na parte aérea, como incrementos do acúmulo de nutrientes foliares e síntese de clorofilas (Baldotto et al., 2009). Estudos recentes, revisados por Baldotto \& Baldotto (2014), apontaram que as substâncias húmicas estimulam a atividade e promoção da síntese das enzimas $\mathrm{H}^{+}$-ATPases da membrana plasmática das células vegetais, num efeito semelhante ao das auxinas (Piccolo, 2001; Nardi et al., 2002; Canellas et al., 2002; Canellas \& Olivares, 2014).

As auxinas sintéticas, denominadas reguladores de crescimento vegetal (Taiz \& Zeiger, 2013), são usadas, em escala comercial como reguladores de crescimento, com resposta dependente da concentração. Essa resposta é análoga à das substâncias húmicas, indicando a necessidade de se estabelecerem as concentrações ótimas para cada fonte e para as diferentes plantas (Baldotto et al., 2009; 2011).

Do ponto de vista da bioatividade, são levantadas as hipóteses de que frações bioativas da matéria orgânica humificada, isoladas nos sistemas integrando lavoura, pecuária e florestas, podem induzir a produção vegetal e, portanto, constituir-se em uma alternativa aos reguladores de crescimento comerciais, possibilitando, ainda, efeitos superiores àqueles obtidos utilizando-se substâncias húmicas isoladas de outros sistemas de manejo menos diversificados. Portanto, parte-se da hipótese de que aspectos positivos da fertilidade do solo (química, física e biológica), verificados para os sistemas de integração lavoura, pecuária e florestas, além de todos os seus demais benefícios econômicos e ambientais, condicionem a formação de substâncias húmicas significativamente mais bioativas, ou seja, com maior capacidade de incrementar o desempenho vegetal (Baldotto \& Baldotto, 2014 e Canellas \& Olivares, 2014).

O objetivo deste trabalho foi avaliar o desempenho inicial do milho em resposta à aplicação de concentrações crescentes de substâncias húmicas isoladas de solos manejados com sistema de integração lavoura, pecuária e florestas, aplicados por via da semente.

\section{MATERIAL E MÉTODOS}

O experimento foi realizado no campus de Florestal da Universidade Federal de Viçosa (1952'55.82"S e $44^{\circ} 25^{\prime} 8.82^{\prime \prime O}$ ), durante o segundo semestre de 2014, em parceria com a Unidade Regional Centro-Oeste da Empresa de Pesquisa Agropecuária de Minas Gerais (19²9’6.73"S e $44^{\circ} 10^{\prime} 44.87^{\prime \prime O}$ ), na qual foram amostrados os solos.

Foi realizada a aplicação de substâncias húmicas isoladas de sistemas com integração lavoura, pecuária e florestas em sementes de milho AG1051, usadas como planta indicadora, por meio da avaliação do seu desempenho inicial (produção de biomassa da parte aérea e das raízes). As substâncias húmicas extraídas dos solos manejados com sistemas com integração lavoura, pecuária e florestas ("Integração") foram comparadas, nas mesmas condições, com as substâncias húmicas isoladas dos solos com plantios de eucalipto (“Eucalipto”) e pastagem ("Pastagem"), isoladamente, bem como com as de uma área de cerrado ("Cerrado") adjacente (Viana et al., 2010; Coelho et al., 2014).

As sementes de milho foram tratadas com concentrações de $0,10,20,40$ e $80 \mathrm{mmol} \mathrm{L}^{-1}$ de carbono orgânico na forma de substâncias húmicas, isoladas de solos sob cada um dos usos (cerrado, eucalipto, pastagem e integração) e caracterizadas conforme a Sociedade Internacional de Substâncias Húmicas (IHSS, 2015), descritas em Baldotto \& Baldotto (2014). O isolamento consistiu na extração com $\mathrm{NaOH} 0,1 \mathrm{~mol} \mathrm{~L}^{-1}$, na proporção solo: extrator igual a 1: 10 (v/v), após agitação por cerca de $4 \mathrm{~h}$, seguida de centrifugação e separação das substâncias húmicas (sobrenadante) e do solo com a fração residual (precipitado). As soluções de substâncias húmicas foram preparadas e ajustadas a $\mathrm{pH} 7$.

A aplicação das substâncias húmicas foi realizada nas sementes, que permaneceram submersas em soluções de cada concentração, referente a cada tratamento, em caixas plásticas tipo gerbox, por $4 \mathrm{~h}$ antes do plantio. As sementes que não foram tratadas com bioestimulantes foram embebidas em água destilada, para que condições análogas de absorção de água fossem proporcionadas a todos os tratamentos.

A unidade experimental consistiu em vasos de $1 \mathrm{dm}^{3}$, preenchidos com solo da camada de 20 a $40 \mathrm{~cm}$ de um Latossolo Vermelho distrófico (Embrapa, 2013), de textura argilosa, o qual apresentou os seguintes dados de análise química para avaliação da fertilidade: $\mathrm{C}=1,63 \mathrm{dag} \mathrm{\textrm {kg } ^ { - 1 }} ; \mathrm{pH}$ $\left(\mathrm{H}_{2} \mathrm{O}\right)=4,0 ; \mathrm{P}$ (Mehlich-1) $=2,2 \mathrm{mg} \mathrm{dm}^{-3} ; \mathrm{K}=15 \mathrm{mg} \mathrm{dm}^{-3}$; $\mathrm{Ca}^{2+}=0,20 \mathrm{cmol}_{\mathrm{c}} \mathrm{dm}^{-3} ; \mathrm{Mg}^{2+}=0,16 \mathrm{cmol}_{\mathrm{c}} \mathrm{dm}^{-3} ; \mathrm{Al}^{3+}=1,71$ $\mathrm{cmol}_{\mathrm{c}} \mathrm{dm}^{-3}, \mathrm{H}+\mathrm{Al}=7,45 \mathrm{cmol}_{\mathrm{c}} \mathrm{dm}^{-3}, \mathrm{SB}=0,40 \mathrm{cmol}_{\mathrm{c}} \mathrm{dm}^{-3}, \mathrm{t}$ $=2,11 \mathrm{cmol} \mathrm{dm}_{c}^{-3}, \mathrm{~T}=7,85 \mathrm{cmol}_{\mathrm{c}} \mathrm{dm}^{-3}, \mathrm{~V}=5 \%$ e m $=81 \%$, Prem $=20 \mathrm{mg} \mathrm{L}^{-1}$.

As doses de corretivos e fertilizantes foram estimadas de acordo com Ribeiro et al. (1999). A calagem foi realizada 30 dias antes da semeadura, de acordo com o recomendado no manual de adubação, por meio do critério da neutralização do alumínio e aumento da disponibilidade de $\mathrm{Ca}$ e de $\mathrm{Mg}$, que resultou em necessidade de calagem de $5 \mathrm{t} \mathrm{ha}^{-1}$ e quantidade de calcário PRNT 85\% igual a 5,94 $\mathrm{g} /$ vaso. Estimou-se a dose de $643 \mathrm{~kg} \mathrm{ha}^{-1}$ de NPK 04-14-08, considerando-se a necessidade de $90 \mathrm{~kg} \mathrm{ha}^{-1}$ de $\mathrm{P}_{2} \mathrm{O}_{5}$ para $\mathrm{P}$ na classe de disponibilidade baixa. Considerando-se uma população final de 50.000 plantas $\mathrm{ha}^{-1}$, essa dose equivaleu a $12,86 \mathrm{~g} \mathrm{vaso}^{-1}$. O solo de cada unidade experimental foi colocado em sacolas plásticas, juntamente com o 
calcário, homogeneizado e umedecido até a capacidade de campo. Após a incubação, foi feita a fertilização do solo de cada unidade experimental, adicionando-se e homogeneizando-se o fertilizante NPK 04-14-08, nas sacolas plásticas com o solo após a incubação com calcário. Em seguida, o solo de cada tratamento foi adicionado a um vaso plástico, no qual foram semeadas seis sementes de milho, sendo realizado o desbaste no quinto dia após a emergência, permanecendo duas plantas por vaso.

O experimento foi desenvolvido em ambiente controlado, em delineamento inteiramente casualizado, com cinco repetições, totalizando 25 unidades experimentais. As unidades experimentais foram monitoradas diariamente, durante todo o experimento e as irrigações visaram a manter a capacidade de campo entre 80 e $100 \%$. As demais variáveis, como controle de plantas daninhas, tratamentos fitossanitários, luminosidade, foram controladas e mantidas iguais e constantes para todos os tratamentos.

Ao final do bioensaio, 45 dias após o plantio, foram determinadas as seguintes variáveis: número de folhas, comprimento da maior folha, largura da parte mediana da maior folha e diâmetro da base. Em seguida, as plantas foram cortadas rente ao solo e pesadas, em balança de precisão, obtendo-se a matéria fresca da parte aérea. As raízes das plantas foram isoladas do solo, cuidadosamente destorroadas e lavadas, para a determinação de sua matéria fresca. Tanto a parte aérea, como o sistema radicular, foram acondicionados em sacos de papel e permaneceram em estufa de ventilação forçada de ar, a $60{ }^{\circ} \mathrm{C}$, por $72 \mathrm{~h}$, tempo suficiente para a desidratação dos materiais vegetais até massa constante para a determinação da matéria seca da parte aérea e da matéria seca das raízes. De posse dos resultados das matérias vegetais de raízes e partes aéreas, secas e frescas, foram obtidos os acúmulos de biomassa fresca e seca totais.

Os resultados foram submetidos à análise de variância e os efeitos quantitativos dos tratamentos (concentrações das substâncias húmicas de cada manejo) foram comparados, por meio de equações de regressão entre as médias das variáveis estudadas e as concentrações de AH. A aplicação do teste $\mathrm{F}$ aos desdobramentos dos fatores, foi realizada a 10,5 e $1 \%$ de probabilidade e os modelos foram testados quando apresentaram coeficiente de determinação superior a 0,60. A comparação entre os manejos foi realizada por meio de contrastes médios, utilizando-se os mesmos testes e níveis de significância (Alvarez V. \& Alvarez, 2003; 2006), utilizando-se o software estatístico Genes (2017).

\section{RESULTADOS}

Os resultados do desempenho inicial das plantas de milho tratadas com concentrações crescentes de substân- cias húmicas isoladas do solo, para cada um dos diferentes manejos, estão apresentados na Tabela 1.

De maneira geral, observou-se que, para todas as variáveis analisadas, houve aumento inicial, acompanhando a elevação da concentração de ácido húmico, seguido de estabilização e de incrementos decrescentes nas maiores concentrações usadas, caracterizando-se um comportamento dependente da concentração (Tabela 2).

As equações de regressão ajustadas entre as variáveis dependentes, estimativas do desempenho das plantas de milho e as concentrações crescentes das substâncias húmicas extraídas, apresentaram comportamento curvilíneo, com variações quadráticas. Nesta mesma tabela, aparecem os valores do coeficiente de determinação de cada equação de regressão. Quando a equação não apresentou grau de ajuste (considerou-se $\mathrm{R}^{2} \geq 0,60$ ) e significância $(\mathrm{P} \leq 0,10)$, foi apresentada a média das concentrações.

Usou-se a equação de regressão para a variável matéria seca total, obtida pela soma da massa seca da parte aérea e das raízes, para estimar a concentração de substância húmica de máxima eficiência física, ou seja, aquela que resultou no maior acúmulo de biomassa das plantas de milho indicadoras. Por meio da derivada da equação de regressão, observou-se que a concentração de 20,89 mmol $\mathrm{L}^{-1}$ de $\mathrm{C}$, na forma de substâncias húmicas isoladas do solo sob integração lavoura, pecuária e floresta, foi a que maximizou o desempenho inicial da planta indicadora de milho, resultando em um acúmulo de 1,59 g/planta, considerando-se a matéria seca total o melhor estimador do acúmulo de biomassa da planta indicadora. Comparado com o tratamento controle, com $0,68 \mathrm{~g} /$ planta de matéria seca total, na melhor concentração de substância húmica, houve incremento de $0,91 \mathrm{~g} /$ planta (133\%), como apresentado na Tabela 1, para os demais tratamentos (manejos). De forma análoga, observa-se nessa mesma tabela, que as substâncias húmicas extraídas do solo sob os demais manejos estudados revelaram que o incremento sobre o controle foi de 81, 79 e 49\%, para cerrado, eucalipto e pastagem, respectivamente, para a melhor concentração de cada tratamento.

Substituindo-se os valores de máxima eficiência (melhor concentração) para cada tratamento (cerrado, eucalipto, pastagem e integração) nas demais equações de regressão da Tabela 2, estimaram-se os valores das outras variáveis estudadas para a condição de máxima eficiência física, apresentados na Tabela 3. Nessa tabela, observam-se, ainda, os incrementos das demais variáveis indicadoras do desempenho inicial da planta de milho sob o tratamento controle para a condição de máxima eficiência física.

Na Tabela 3, verifica-se que, de forma geral, as variáveis que estimam o desempenho da planta indicadora de 
milho foram incrementadas positivamente pelo tratamento com as substâncias húmicas, com destaque, entretanto, para a bioatividade daquelas isoladas do solo manejado com integração.

A Tabela 4 mostra os contrastes médios significativos para o efeito da integração sobre os demais sistemas, isoladamente. O primeiro contraste da tabela compara o controle (tratamento das sementes de milho com água, sem substâncias húmicas) com os demais tratamentos (aplicação de substâncias húmicas isoladas dos solos sob cerrado, eucalipto, pastagem e integração). Os demais contrastes compararam as bioatividades do cerrado e da integração, da pastagem com a integração, do eucalipto frente à integração e da pastagem e do eucalipto contra a integração.

\section{DISCUSSÃO}

De forma análoga aos resultados apresentados, para a curva de resposta ao tratamento com substâncias húmicas em milho e outras culturas (Nardi et al., 2002; Canellas et al., 2002; Baldotto et al., 2009; Baldotto \& Baldotto, 2013), observou-se, na Figura 1, que para todas as variáveis analisadas, houve comportamento dependente da concentração de ácido húmico. Ou seja, o acúmulo de biomassa das

Tabela 1. Produção de matéria seca total (MST) das plantas indicadoras de milho em resposta à aplicação de substâncias húmicas extraídas de solos sob diferentes manejos, para a concentração de máxima eficiência física (MEF), estimada pelas derivadas das equações de regressão da figura 1, acompanhadas pela comparação com o controle

\begin{tabular}{|c|c|c|c|c|c|}
\hline \multirow[t]{2}{*}{ Manejo $^{(1)}$} & \multirow{2}{*}{$\begin{array}{c}\text { Concentração de MEF } \\
\text { mmol }{\mathrm{L} \mathrm{de} \mathrm{C}^{-1}}^{-1}\end{array}$} & MST & \multirow{2}{*}{ Controle } & \multicolumn{2}{|c|}{ Diferença $^{(2)}$} \\
\hline & & & & g/planta & $\%$ \\
\hline Cerrado & 26,71 & 1,2369 & & $0,5519^{\circ}$ & 81 \\
\hline Eucalipto & 20,50 & 1,2293 & & $0,5443^{\circ}$ & 79 \\
\hline Pastagem & 21,69 & 1,0214 & 0,6850 & 0,3364 & 49 \\
\hline Integração & 20,89 & 1,5938 & & $0,9088 *$ & 133 \\
\hline
\end{tabular}

(1) Manejo: Cerrado = área de cerrado adjacente; Integração = integração lavoura, pecuária (pastagem de braquiária) e floresta de eucalipto; Eucalipto = eucalipto convencional; Pastagem $=$ pastagem convencional de braquiária; ${ }^{(2)}$ Diferença $=\{[($ maior média - menor média $) /$ menor média] $* 100\} ; * \mathrm{e}^{\circ}=$ significativo a 5 e $10 \%$ de probabilidade pelo teste $\mathrm{F}$, respectivamente.

Tabela 2: Equações de regressão e coeficientes de determinação $\left(\mathrm{R}^{2}\right)$ para acúmulo de biomassa fresca e seca da parte aérea e das raízes das plantas indicadoras de milho, em resposta à aplicação de substâncias húmicas extraídas de solos sob diferentes manejos

\begin{tabular}{|c|c|c|c|}
\hline Variável $^{(1)}$ & Manejo $^{(2)}$ & Equação de Regressão & $\mathbf{R}^{2}$ \\
\hline \multirow{4}{*}{ MFPA (g/planta) } & Cerrado & $\widehat{y}=$ média $=4,9742$ & \\
\hline & Eucalipto & $\widehat{y}=3,7164+0,4276 x-0,0098^{\circ} x^{2}$ & 0,7366 \\
\hline & Pastagem & $\widehat{y}=$ média $=5,9033$ & \\
\hline & Integração & $\widehat{y}=3,7848+0,6551 x-0,0156^{\circ} x^{2}$ & 0,7896 \\
\hline \multirow{4}{*}{ MSPA (g/planta) } & Cerrado & $\widehat{y}=0,4854+0,0234 x-0,0004 * x^{2}$ & 0,7144 \\
\hline & Eucalipto & $\hat{y}=0,3369+0,0511 x-0,0012^{\circ} x^{2}$ & 0,8022 \\
\hline & Pastagem & $\hat{y}=0,3636+0,0390 x-0,0008^{\circ} x^{2}$ & 0,6756 \\
\hline & Integração & $\widehat{y}=0,3763+0,0751 x-0,0018^{\circ} x^{2}$ & 0,8121 \\
\hline \multirow{4}{*}{ MFR (g/planta) } & Cerrado & $\widehat{y}=$ média $=2,5146$ & \\
\hline & Eucalipto & $\widehat{y}=2,5580+0,1425 x-0,0038^{\circ} x^{2}$ & 0,8539 \\
\hline & Pastagem & $\widehat{y}=$ média $=2,9385$ & \\
\hline & Integração & $\widehat{y}=$ média $=3,5977$ & 0,6000 \\
\hline \multirow{4}{*}{ MSR (g/planta) } & Cerrado & $\widehat{y}=0,2258+0,0103 x-0,0002 * x^{2}$ & 0,7107 \\
\hline & Eucalipto & $\hat{y}=0,2137+0,0210 x-0,0005^{*} x^{2}$ & 0,8041 \\
\hline & Pastagem & $\hat{y}=0,2459+0,0173 x-0,0005 * x^{2}$ & 0,9027 \\
\hline & Integração & $\hat{y}=0,2192+0,0118 x-0,0002 * x^{2}$ & 0,6649 \\
\hline \multirow{4}{*}{ MFT (g/planta) } & Cerrado & $\widehat{y}=$ média $=7,4888$ & \\
\hline & Eucalipto & $\hat{y}=6,2744+0,5701 x-0,0136 * x^{2}$ & 0,7818 \\
\hline & Pastagem & $\widehat{y}=$ média $=8,8418$ & \\
\hline & Integração & $\hat{y}=6,1543+0,7977 x-0,0186 * x^{2}$ & 0,8311 \\
\hline
\end{tabular}

${ }^{(1)}$ Variável: MFR, MSR, MFPA, MSPA, MFT e MST = matérias frescas secas das raízes, da parte aéreas e totais; ${ }^{(2)}$ Manejo: Cerrado = área de cerrado adjacente; Integração = integração lavoura, pecuária (pastagem de braquiária) e floresta de eucalipto; Eucalipto = eucalipto convencional; Pastagem = pastagem convencional de braquiária. 
plantas indicadoras de milho apresentou resposta curvilinear (equações quadráticas) à aplicação do bioestimulante, possibilitando a determinação de uma concentração de máxima eficiência.

Considera-se que a decomposição dos resíduos vegetais no solo não destrua, ao menos totalmente, as suas substâncias bioativas (e.g., resíduos de auxinas), as quais persistem e se estabilizam junto com as substâncias húmicas (Nardi et al., 2002; Canellas et al., 2002). Os modelos conceituais de estrutura das substâncias húmicas (macromolecular e supramolecular), revisados por Baldotto \& Baldotto (2014) e por Canellas et al. (2014), dão suporte à hipótese e os dados experimentais fornecem indicações do mecanismo de bioatividade.

As bases celulares e moleculares da atuação das substâncias humificadas da matéria orgânica do solo advêm de estudos que apontam a estimulação da atividade e a promoção da síntese das enzimas $\mathrm{H}^{+}$-ATPases da membrana plasmática, ou seja, efeito semelhante ao auxínico (Façanha et al., 2002). Façanha et al. (2002) demonstraram que ácidos húmicos, isolados de vermicompostos e de lodo de esgoto, promoveram o desenvolvimento radicular de plântulas de milho e de café e a ativação da $\mathrm{H}^{+}$-ATPase de membrana plasmática. As $\mathrm{H}^{+}$-ATPases são enzimas transmembranares capazes de hidrolizar ATP, gerando energia e um gradiente eletroquímico que está diretamente envolvido em dois mecanismos fundamentais para o desenvolvimento vegetal:

(i) energização do sistema secundário de translocação de íons, o que é fundamental para absorção de macro e micronutrientes (Sondergaard et al., 2004), mecanismo que pode ser explicado pela ação das $\mathrm{H}^{+-}$ATPases na despolarização da membrana plasmática e, consequentemente, na ativação de transportadores;

(ii) promoção do aumento da plasticidade da parede celular por acidificação do apoplasto, fator fundamental para o processo de crescimento e alongamento da célula vegetal (Cosgrove, 1997). Esse último mecanismo está relacionado com a teoria do crescimento ácido, que postula que o aumento de extrusão de prótons, mediado pela $\mathrm{H}^{+}$ATPase da membrana plasmática, induz a ação de enzimas específicas, que atuam sobre a parede celular, aumentando sua plasticidade e, consequentemente, permitindo o alongamento da célula (Rayle \& Cleland, 1992), concor-

Tabela 3: Acúmulo de biomassa fresca e seca da parte aérea e das raízes das plantas indicadoras de milho, em resposta à aplicação de substâncias húmicas extraídas de solos sob diferentes manejos, para a concentração de máxima eficiência física (MEF), estimada pelas derivadas das equações de regressão para a produção de biomassa total (matéria seca da parte aérea e das raízes), apresentada na Figura 1, acompanhadas pela comparação com o controle (diferença numérica e percentual)

\begin{tabular}{|c|c|c|c|c|c|}
\hline \multirow{2}{*}{ Variável $^{(1)}$} & \multirow{2}{*}{ Manejo $^{(2)}$} & MEF & \multicolumn{2}{|c|}{ Controle } & \multirow{2}{*}{$\begin{array}{c}\text { Diferença }^{(3)} \\
\%\end{array}$} \\
\hline & & & g/planta & & \\
\hline \multirow{4}{*}{$\operatorname{MFPA}(\mathrm{g} /$ planta $)$} & Cerrado & 4,9742 & 4,4700 & 0,5042 & 11 \\
\hline & Eucalipto & 8,3638 & & $3,8938 * *$ & 87 \\
\hline & Pastagem & 5,9033 & & $1,4333^{\circ}$ & 32 \\
\hline & Integração & 10,6585 & & $6,1885^{* *}$ & 138 \\
\hline \multirow{4}{*}{ MSPA(g/planta) } & Cerrado & 0,797 & 0,4400 & $0,3570^{\circ}$ & 81 \\
\hline & Eucalipto & 0,8802 & & $0,4402 *$ & 100 \\
\hline & Pastagem & 0,8269 & & $0,3869 *$ & 88 \\
\hline & Integração & 1,1594 & & $0,7194 * *$ & 164 \\
\hline \multirow{4}{*}{ MFR(g/planta) } & Cerrado & 2,5146 & 2,7217 & $-0,2071$ & -8 \\
\hline & Eucalipto & 3,8823 & & $1,1606^{\circ}$ & 43 \\
\hline & Pastagem & 2,9385 & & 0,2168 & 7 \\
\hline & Integração & 3,5977 & & $0,8760^{\circ}$ & 32 \\
\hline \multirow{4}{*}{ MSR(g/planta) } & Cerrado & 0,3529 & 0,2450 & $0,1079^{\circ}$ & 44 \\
\hline & Eucalipto & 0,4341 & & $0,1891^{*}$ & 77 \\
\hline & Pastagem & 0,3874 & & $0,1424^{\circ}$ & 58 \\
\hline & Integração & 0,3771 & & $0,1321^{\circ}$ & 54 \\
\hline \multirow{4}{*}{ MFT(g/planta) } & Cerrado & 7,4888 & 7,1917 & 0,2971 & 4 \\
\hline & Eucalipto & 12,2461 & & $5,0544 *$ & 70 \\
\hline & Pastagem & 8,8418 & & 1,6501 & 23 \\
\hline & Integração & 14,6905 & & $7,4988 * *$ & 104 \\
\hline
\end{tabular}

(1)Variável: MFR, MSR, MFPA, MSPA, MFT e MST = matérias frescas secas das raízes, da parte aéreas e totais; (2)Manejo: Cerrado = área de cerrado adjacente; Integração = integração lavoura, pecuária (pastagem de braquiária) e floresta de eucalipto; Eucalipto = eucalipto convencional; Pastagem $=$ pastagem convencional de braquiária; ${ }^{(3)}$ Diferença $=\{[($ maior média - menor média $) /$ menor média $] * 100\} ; *$ e ${ }^{\circ}=$ significativo a 5 e $10 \%$ de probabilidade pelo teste $\mathrm{F}$, respectivamente. 
dando, assim, com vários trabalhos que relatam a presença de auxinas na estrutura supramolecular dos ácidos húmicos (Canellas et al., 2002; Trevisan et al., 2010).

A resposta positiva das plantas indicadoras de milho às substâncias húmicas extraídas dos solos sob diferentes usos (cerrado, eucalipto, pastagem e integração), neste estudo, indicaram que as condições ecológicas possibilitaram a presença e a proteção de substâncias bioativas (e.g., auxínicas) nas associações moleculares húmicas. Os resultados apontaram, portanto, para oportunidades tecnológicas para a agricultura tropical, em convergência com a necessidade de desenvolvimento de novos insumos.

Vale ressaltar, ainda, que a alta bioatividade observada para as substâncias húmicas isoladas do solo manejado com integração lavoura, pecuária e floresta, foi mais intensa e, acompanhada, na sequência, por cerrado e eucalipto, com efeitos estimulantes análogos sobre o controle, seguidos da pastagem, que apresentou menor capacidade reguladora de crescimento que a testemunha. Os contrastes significativos para o efeito da integração sobre os demais sistemas, isoladamente, confirmam que a bioatividade desse sistema mais complexo é um fator positivo para explicar o melhor desempenho observado para o cultivo conjunto de lavoura, pecuária e florestas, em comparação com o dos monocultivos, como vem sendo observado na literatura (Macedo, 2009; Vilela et al., 2011; Oliveira et al., 2015).

O custo de extração das substâncias húmicas é baixo, uma vez que eles podem ser preparados com resíduos orgânicos recicláveis e de forma artesanal, inclusive pela agricultura familiar. Os procedimentos de extração são simples, podendo ser adaptados para uma empresa rural, sem maiores impactos de resíduos do processo de obtenção. Como são aplicadas concentrações baixas, o processo de extração, mesmo se operacionalizado por empresas comerciais, chegará ao produtor com preços acessíveis, que não onerarão demasiadamente o custo de produção. O custo/ benefício é baixo e, para a análise econômica, usa-se, praticamente o custo de aplicação, face ao qual o custo de preparo pode ser desprezado, tendo sido estimado em um dia de trabalho de um operário com formação de ensino médio (Baldotto \& Baldotto, 2014).

Pelos resultados obtidos neste estudo, é estrategicamente adequado incentivar o uso de substâncias húmicas, tanto pela agricultura de grandes áreas e produtividades, como pela agricultura orgânica, comumente familiar, uma vez que a sua bioatividade adequa-se a todas essas modalidades, sem incompatibilidade com seus sistemas de produção, estimulando a absorção de nutrientes a partir da restituição com fertilizantes minerais, orgânicos ou ambos, incluindo, ainda, efeitos adicionais, como por exemplo, de ordem metabólica, condicionadora e protetora (Baldotto et al., 2014). 


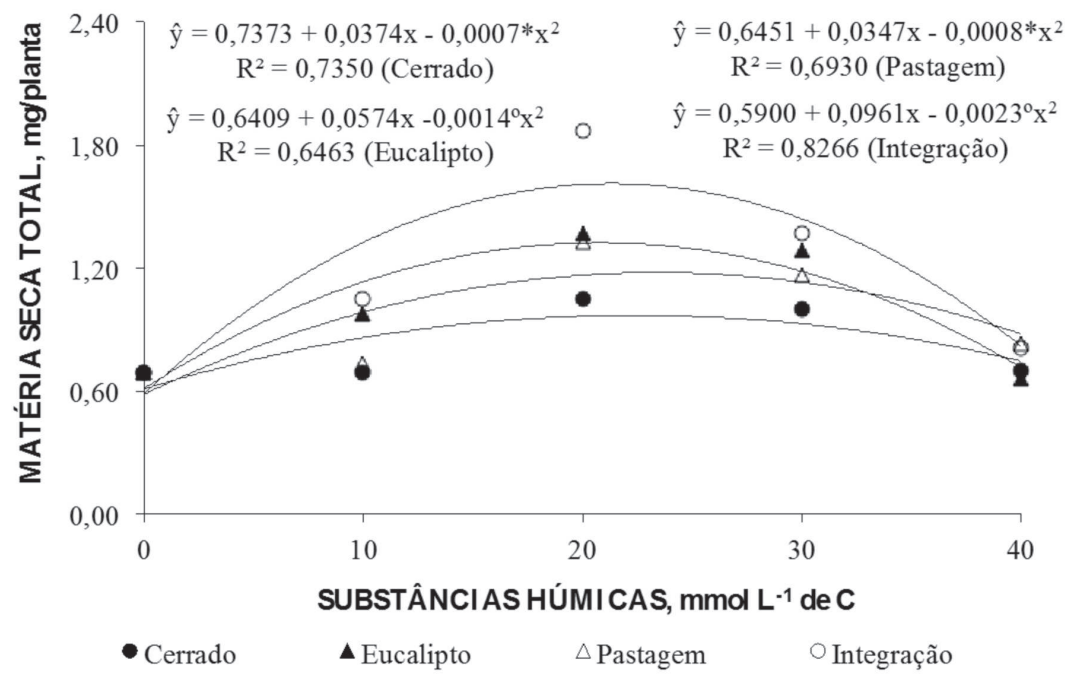

Figura 1: Produção de matéria seca total (MST) das plantas indicadoras de milho em resposta à aplicação de substâncias húmicas extraídas de solos sob diferentes manejos: Cerrado = área de cerrado adjacente; Integração = integração lavoura, pecuária (pastagem de braquiária) e floresta de eucalipto; Eucalipto = eucalipto convencional; Pastagem = pastagem convencional de braquiária.

\section{CONCLUSÕES}

A resposta de crescimento, das plantas indicadoras de milho, ao tratamento de sementes com as substâncias húmicas resulta em incrementos positivos e quadráticos, convergindo ao mecanismo de efeito bioestimulante auxínico.

As substâncias húmicas de todos os quatro tipos de manejo testados apresentam bioatividade maior que a do controle (100\%) e a ordem dos efeitos foi integração (233\%) $>$ cerrado $(181 \%) \sim$ eucalipto $(179 \%)>$ pastagem $(149 \%)$.

As concentrações de substâncias húmicas que resultam em máximo acúmulo de matéria seca total das plantas indicadoras de milho pouco variam (de 20,50 a 26,71 mmol $\mathrm{L}^{-1}$ de $\mathrm{C}$ na forma de substâncias húmicas), mas as substâncias húmicas obtidas do sistema de integração lavoura, pecuária e florestas são 29, 30 e 56\% mais bioativas do que aquelas extraídas dos solos isoladamente manejados com cerrado, eucalipto e pastagem, respectivamente.

\section{AGRADECIMENTOS}

Este trabalho contou com financiamentos do CNPq, da FAPEMIG e da FUNARBE. Os autores agradecem aos estudantes, funcionários e professores da Universidade $\mathrm{Fe}$ deral de Viçosa e da Unidade Regional Centro-Oeste da Empresa de Pesquisa Agropecuária de Minas Gerais, os quais prestaram continuamente seu apoio para a realização deste projeto.

\section{REFERÊNCIAS}

Alvarez V VH \& Alvarez GAM (2003) Apresentação de equações de regressão e suas interpretações. Boletim Informativo da Sociedade Brasileira de Ciência do Solo, 28:28-32.
Alvarez VHV \& Alvarez GAM (2006) Comparações de médias ou testes de hipóteses e contrastes. Boletim Informativo da Sociedade Brasileira de Ciência do Solo, 31:24-34.

Baldotto LEB, Baldotto MA, Giro VB, Canellas LP, Olivares FL \& Bressan-Smith R (2009) Desempenho do abacaxizeiro 'Vitória' em resposta à aplicação de ácidos húmicos durante aclimatação. Revista Brasileira de Ciência do Solo, 33: 979-990.

Baldotto MA, Muniz RC, Baldotto LEB \& Dobbss LB (2011) Root growth of Arabidopsis thaliana (L.) Heynh. treated with humic acids isolated from typical soils of Rio de Janeiro state, Brazil. Revista Ceres, 58:504-511.

Baldotto MA \& Baldotto LEB (2013) Gladiolus development in response to bulb treatment with different concentrations of humic acids. Revista Ceres, 60:138-142.

Baldotto MA \& Baldotto LEB (2014) Ácidos húmicos. Revista Ceres, 61:856-881.

Canellas LP, Façanha AO, Façanha AR \& Olivares FL (2002) Humic acids isolated from earthworm induces root mitotic sites and plasma membrane H+-ATPase. Plant Physiology, 30:19511957.

Canellas LP \& Olivares FL (2014) Physiological responses to humic substances as plant growth promoter. Chemical and Biological Technologies in Agriculture, 1:03-14.

Coelho JS, Araújo SAC, Viana MCM, Villela SDJ, Freire FM \& Braz TGS (2014) Morfofisiologia e valor nutritivo do capimbraquiária em sistema silvipastoril com diferentes arranjos espaciais. Semina: Ciências Agrárias, 35:1487-1500.

Cosgrove DJ (1997) Relaxation in a high-stress environment: The molecular bases of extensible cell walls and cell enlargement. Plant Cell, 9:1031-1041.

Embrapa - Empresa Brasileira de Pesquisa Agropecuária (2013) Sistema Brasileiro de Classificação de Solos. $3^{\mathrm{a}}$ ed. Rio de Janeiro, Centro Nacional de Pesquisa em Solos. 353p.

Façanha AR, Façanha ALO, Olivares FL, Guridi F, Santos GA, Velloso ACX, Rumjanek VM, Brasil F, Schripsema J, Braz-Filho R, Oliveira MA \& Canellas LP (2002) Bioatividade de ácidos húmicos: Efeito sobre o desenvolvimento radicular e sobre a bomba de prótons da membrana plasmática. Pesquisa Agropecuária Brasileira, 37:1301-1310. 
Genes (2017) Programa Genes. Disponível em: <http:// arquivo.ufv.br/genetica/WebSite1/Default.aspx>. Acessado em: 21 de agosto de 2017.

IHSS - International Humic Substances Society (2017) Products. Disponível em: <http://www.ihss.gatech.edu/products.html>. Acessado em: 21 de agosto de 2017.

Macedo MCM (2009) Integração lavoura e pecuária: o estado da arte e inovações tecnológicas. Revista Brasileira de Zootecnia, 38:133-146.

Nardi S, Pizzeghello D, Muscolo A \& Vianello A (2002) Physiological effects of humic substances on higher plants. Soil Biology and Biochemistry, 34:1527-1536.

Oliveira FFLR, Cabacinha CD, Santos LDT, Barroso DG, Santos Júnior A, Brant MC \& Sampaio RA (2015) Crescimento inicial de eucalipto e acácia, em diferentes arranjos de integração lavoura-pecuária-floresta. Cerne, 21:227-233.

Piccolo A (2001) The supramolecular structure of humic substances. Soil Science, 166:810-832.

Rayle DL \& Cleland RE (1992) The acid growth theory of auxin induced cell elongation is alive and well. Plant Physiology, 99:1271-1274.

Ribeiro AC, Guimarães PTG \& Alvarez V VH (1999) Recomendações para uso de corretivos e fertilizantes em Minas Gerais: 5 Aproximação. Viçosa, Comissão de Fertilidade do Solo do Estado de Minas Gerais. 359p
Sondergaard TE, Schulza A \& Palmgren MG (2004) Energization of transport processes in plants. Roles of plasma membrane H+-ATPase. Plant Physiology, 136:2475-2482.

Taiz L \& Zeiger E (2013) Fisiologia vegetal. $5^{\text {a }}$ ed. Porto Alegre, Artmed. 954p.

Trevisan S, Francioso O, Quaggiotti S \& Nardi S (2010) Humic substances biological activity at the plant-soil interface from environmental aspects to molecular factors. Plant Signaling \& Behavior, 5: 635-643.

Viana MCM, Mascarenhas MHT, Queiroz DS, Magalhaes LL, Melido RCN, Ofugi C \& Gomes RJ (2010) Experiências com o Sistema de Integração Lavoura-Pecuária-Floresta em Minas Gerais. Informe Agropecuário, 31:98111.

Vilela L, Martha Junior GB, Macedo MCM, Marchão RL, Guimaraes Junior R, Pulrolnik K \& Maciel GA (2011) Sistemas de integração lavoura-pecuária na região do Cerrado. Pesquisa Agropecuária Brasileira, 46:1127-1138. 